\section{Commentary: Increased Windkessel effect is a sign of aortic aneurysm}

\author{
Tohru Asai, MD, PhD
}

Viscoelastic compliance allows the aorta to serve as an important pressure-moderating reservoir. The aorta stretches as internal pressure rises during systole and recoils as pressure falls during diastole. This "Windkessel effect" smooths the fluctuations in pulse pressure to maintain distal organ perfusion during diastole. Replacement of the ascending aorta with a polyester graft is thought to lose part of that Windkessel effect and to increase aortic input impedance and pressure amplitude, as represented in some mathematical models. ${ }^{1}$ Replacement of the ascending aorta with a noncompliant prosthesis increases wall tension and rate of pressure rise in the residual aorta in an in vitro model. ${ }^{2}$ There is concern that such hemodynamic change with a vascular prosthesis may impair distal organ perfusion and/or increase risks for aortic aneurysm development after surgery. ${ }^{3}$

In this issue of the Journal, Salvi and colleagues ${ }^{4}$ present their study to evaluate outcomes of altered aortic distensibility by using pulse waveform analysis before and after replacement of the ascending aorta. The carotid artery pulse waveforms were recorded by a percutaneous, noninvasive method. The 30 recruited patients were varied in their etiologies, 12 with bicuspid aortopathy, 5 with Marfan syndrome, and 3 with previous aortic valve replacement. All patients underwent aortic root replacement with the Valsalva polyester prosthesis: 6 reimplantations, 9 biological valved conduits, and 15 mechanical valved conduits.

This study is the first in humans to assess the pulse waveform to investigate the effect of changed stiffness of the aorta following replacement of the ascending aorta with late follow-up data. Noninvasive measurements were

\footnotetext{
From the Department of Cardiovascular Surgery, Juntendo University, Tokyo, Japan. Disclosures: The author reported no conflicts of interest.

The Journal policy requires editors and reviewers to disclose conflicts of interest and to decline handling or reviewing manuscripts for which they may have a conflict of interest. The editors and reviewers of this article have no conflicts of interest.

Received for publication May 23, 2020; revisions received May 23, 2020; accepted for publication May 28, 2020; available ahead of print June 26, 2020.

Address for reprints: Tohru Asai, MD, PhD, Department of Cardiovascular Surgery, Juntendo University, Faculty of Medicine, 2-1-1, Hongo, Bunkyo-ku, Tokyo 1138421, Japan (E-mail: t.asai.jj@juntendo.ac.jp).

J Thorac Cardiovasc Surg 2022;163:1294-5

$0022-5223 / \$ 36.00$

Copyright (C) 2020 by The American Association for Thoracic Surgery

https://doi.org/10.1016/j.jtcvs.2020.05.113
}

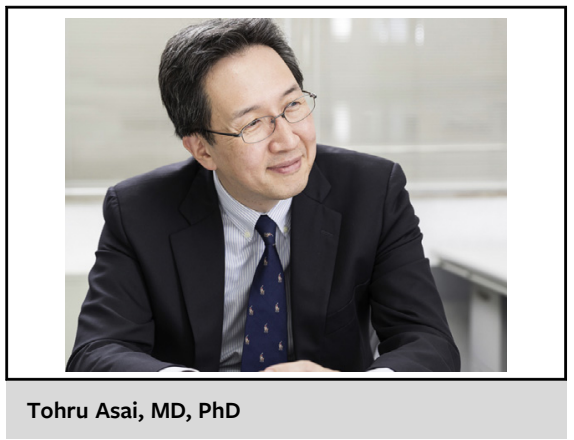

CENTRAL MESSAGE

The Windkessel effect in an aneurysmal aorta is greater than normal, but the hemodynamic changes associated with prosthetic replacement invite further elucidation.

made by experienced technicians, so the method should be reproducible in other institutions. The authors did not confirm the hypothesis that a prosthetic replacement of the ascending aorta causes serious hemodynamic alteration downstream in the mid-term, and they found also, as expected, that the aneurysmal ascending aorta demonstrated a slow uptake of the pulse waveform, a so-called "pulsus tardus."

However, "pulsus tardus et parvus" is a well-known physical sign of aortic valve stenosis. One may wonder why this study recruited patients all with aortic root procedures. They obviously had some aortic valve pathology. If the authors' primary interest was hemodynamic alteration after aortic replacement with a less-elastic prosthesis, then aortic valve pathology and left ventricular remodeling would be confounding factors. To elucidate possible changes with less-compliant prosthesis, one might do better to recruit patients undergoing supracoronary ascending aortic replacement, or even longer replacements such as descending aorta or thoracoabdominal aorta. Our readers may wonder about etiology-specific characteristics, such as how the effects of bicuspid aortopathy differ from those of Marfan syndrome, and the role of different procedures, such as valve replacement versus valve-sparing procedures, straight grafts versus Valsalva grafts, and the size or length of prosthesis. Even more questions will certainly arise, unanswered by the current study. However, I believe that Salvi 
and colleagues have certainly opened the door for the use of physiological analysis to explore aortic pathophysiology and hemodynamic consequences after surgical intervention.

\section{References}

1. Bauernschmitt R, Schulz S, Schwarzhaupt A, Kiencke U, Vahl CF, Lange R, et al. Simulation of arterial hemodynamics after partial prosthetic replacement of the aorta. Ann Thorac Surg. 1999;67:676-82.
2. Scharfschwerdt M, Sievers HH, Greggersen J, Hanke T, Misfeld M. Prosthetic replacement of the ascending aorta increases wall tension in the residual aorta. Ann Thorac Surg. 2007;83:954-7.

3. Simon-Kupilik N, Schima H, Huber L, Moidl R, Wipplinger G, Losert U, et al. Prosthetic replacement of the aorta is a risk factor for aortic root aneurysm development. Ann Thorac Surg. 2002:73:455-9.

4. Salvi L, Alfonsi J, Grillo A, Pini A, Soranna D, Zambon A, et al. Postoperative and mid-term hemodynamic changes after replacement of the ascending aorta. $J$ Thorac Cardiovasc Surg. 2022;163:1283-92. 